Pat M. Fidopiastis · Henning Sørum • Edward G. Ruby

\title{
Cryptic luminescence in the cold-water fish pathogen Vibrio salmonicida
}

\begin{abstract}
The recent discovery that the fish pathogen Vibrio salmonicida is closely related to the luminous bacteria Vibrio fischeri and Vibrio logei suggested that $V$. salmonicida might also be capable of bioluminescence. Interestingly, cells of $V$. salmonicida were found to produce light in culture, but only when exposed to either an aliphatic aldehyde and/or the major $V$. fischeri autoinducer $N$-(3-oxo-hexanoyl)-L-homoserine lactone, a transcriptional activator of the luminescence (lux) genes. An extract of spent medium of $V$. salmonicida that should contain any $V$. salmonicida acyl-homoserine lactone autoinducer, when added to $V$. fischeri cells, led to an induction of their luminescence. These results show that $V$. salmonicida is a newly recognized luminous bacterial species that apparently both produces an autoinducer activity and responds to exogenous $V$. fischeri autoinducer.
\end{abstract}

\section{Introduction}

Vibrio salmonicida is a psychrophilic bacterium that is the causative agent of cold-water vibriosis in Atlantic salmon (Salmo salar), rainbow trout (Oncorhynchus mykiss), and cod (Gadus morhua) (Egidius 1986; Wiik et al. 1989;
Sørum et al. 1990). Analyses of $16 S$ rRNA gene sequences have revealed a close phylogenetic relationship between $V$. salmonicida and the luminous marine bacteria Vibrio fischeri and Vibrio logei (Wiik et al. 1995; Fidopiastis et al. 1998). However, phenotypic characterization has shown that $V$. salmonicida is metabolically quite distinct from both of those species (Farmer and HickmanBrenner 1991). Since several other marine luminous bacterial species cluster phylogenetically (Nealson and Hastings 1991), we examined isolates of $V$. salmonicida, a species not previously known to be luminous, for visible luminescence in culture. Interestingly, we discovered that cultures of this species did produce detectable luminescence if they were supplemented with an aliphatic aldehyde.

Bacterial luminescence results from the activity of luciferase, a mixed function oxidase that couples the oxidation of reduced flavin mononucteotide $\left(\mathrm{FMNH}_{2}\right)$ and an aliphatic aldehyde by $\mathrm{O}_{2}$, yielding light as a product. The genes encoding the enzymes required for luminescence have been examined in at least five species and are typically organized in a single operon (Nealson and Hastings 1991). In each case, the operon contains the luciferase genes (lux $A$ and $B$ ) and those encoding the synthesis of aldehyde substrate (luxC, $D$, and $E$ ), while in $V$. fischeri the locus also contains two regulatory genes, luxI [the VAI-1 autoinducer synthase gene; VAI-1 is the V. fischeri autoinducer $N$-(3-oxo-hexanoyl)-L-homoserine lactone] and $\operatorname{luxR}$ (the VAI-1 receptor gene). The luciferase and aldehyde synthesis genes have been shown to be cotranscribed, and the regulation of this operon in several species is influenced by the concentration of an acyl-homoserine lactone (acyl-HSL) autoinducer (Nealson and Hastings 1991).

The ability to produce light indicated that $V$. salmonicida expresses luciferase genes; however, the apparent requirement for exogenous aldehyde suggested that $\mathrm{V}$. salmonicida either may lack the genes for aliphatic aldehyde synthesis or, alternatively, may uncouple the regulation of $\operatorname{lux} A$ and $B$ from lux $C, D$, and $E$ (Nealson 1977; Fuqua et al. 1996). In the latter case, $V$. salmonicida might sepa- 
rately regulate aldehyde synthesis (and, thus, luminescence) only in response to the presence of an acyl-HSL autoinducer produced by other luminous bacteria (Visick and Ruby 1998). In this study, we describe some aspects of the physiology of luminescence of $V$. salmonicida, and discuss our results in the light of two important questions first posed by Nealson and Hastings (1991):

1. Are there groups of bacteria that possess genes for luciferase (or aldehyde synthesis) but do not normally express them?

2. Is luminescence the primary role for luciferase in luminous bacteria?

\section{Materials and methods}

Determination of luminescence on agar plates

V. salmonicida strains NCMB 2262 (Egidius et al. 1986; Table 1), VS1, VS201, VS224, and VS420 (Sørum et al. 1988), each isolated from diseased Atlantic salmon, were streaked onto a seawater-tryptone-yeast extract (SWT) agar medium (Boettcher and Ruby 1990) and incubated for up to 8 days at either 2 , 8 , or $16^{\circ} \mathrm{C}$. From the time they first appeared and throughout their subsequent growth, individual colonies were removed and their luminescence was measured in a sensitive photometer (TD-20/20 Luminometer; Turner Designs, Sunnyvale, Calif., USA) either with or without exposure to fumes of decyl aldehyde (Sigma-Aldrich, St. Louis, Mo., USA).

\section{Luciferase enzyme kinetics}

Luciferase activity was assayed in vitro as described previously (Nealson 1978), with the exception that reactions were performed at $24^{\circ} \mathrm{C}$ rather than at $30^{\circ} \mathrm{C}$. Briefly, several colonies from overnight cultures grown on SWT agar plates were placed into separate Eppendorf tubes containing $1.0 \mathrm{ml}$ cold lysis buffer $(10 \mathrm{mM} \mathrm{Na}$ EDTA, pH 7.5; 1 mM dithiothreitol); the cell suspension was vor-

Table 1 Luciferase enzyme decay kinetics of some bacterial strains used in this study

\begin{tabular}{|c|c|c|}
\hline Species & Source, reference & $\begin{array}{l}\text { Luciferase in } \\
\text { vitro turnover } \\
\text { kinetics } \\
\left(\mathrm{T}_{1 / 2}, \text { in } \mathrm{s}\right)\end{array}$ \\
\hline \multicolumn{3}{|l|}{ Vibrio harveyi } \\
\hline B392 & Seawater $^{\mathrm{a}}$ & 17 \\
\hline \multicolumn{3}{|l|}{ Vibrio logei } \\
\hline SA6 & Sepiola affinis light organ ${ }^{\mathrm{b}}$ & 2.2 \\
\hline SR6 & Sepiola robusta light organ ${ }^{\mathrm{b}}$ & 2.1 \\
\hline \multicolumn{3}{|l|}{ Vibrio fischeri } \\
\hline SA1 & Sepiola affinis light organ ${ }^{\mathrm{b}}$ & 1.7 \\
\hline SR5 & Sepiola robusta light organ ${ }^{\mathrm{b}}$ & 2.0 \\
\hline ES114 & Euprymna scolopes light organ ${ }^{c}$ & 0.7 \\
\hline \multicolumn{3}{|c|}{ Vibrio salmonicida } \\
\hline NCMB 2262 & Diseased Atlantic salmon $^{\mathrm{d}}$ & 2.0 \\
\hline
\end{tabular}

a Reichelt and Baumann (1973)

${ }^{\mathrm{b}}$ Fidopiastis et al. (1998)

${ }^{\mathrm{c}}$ Boettcher and Ruby (1990)

${ }^{\mathrm{d}}$ Egidius et al. (1986) texed and then incubated on ice for 20 min. Twenty-microliter aliquots of each of the resulting cell lysates were then added to separate 5 -ml glass vials containing $10 \mu \mathrm{l} 0.01 \%$ dodecyl aldehyde (Sigma-Aldrich) suspension in $10 \mathrm{mM}$ potassium phosphate buffer (pH 7.1). The vials were placed into a light-tight photometer chamber, and $1 \mathrm{ml}$ of a $50 \mu \mathrm{M}$ solution of $\mathrm{FMNH}_{2}$ was injected into each. The resulting level of light emission was continuously recorded on a strip chart recorder, and the values at intervals of $1 \mathrm{~s}$ were plotted to calculate the enzyme turnover kinetics from the rate of decay of luminescence.

Luminescence induction in the presence of added aldehyde

Five strains of $V$. salmonicida were inoculated separately into each of two sets of flasks containing either SWT broth or a $V$. harveyiconditioned SWT broth (VHCM). VHCM was prepared as described previously (Makemson 1973) to remove an inhibitor of luminescence induction. The flasks were shaken at either 8 or $16^{\circ} \mathrm{C}$, and aliquots were taken throughout growth of the culture and measured for both optical density (OD) at $600 \mathrm{~nm}$ and luminescence. The luminescence measurements were made both with and without exposure to a final decyl aldehyde concentration of $50 \mathrm{ng} / \mathrm{ml}$ which was added at the time of measurement.

Effect of the addition of VAI-1 on luminescence induction

Cells of either $V$. fischeri strain ES114, V. logei strain SR6, or $V$. salmonicida strain NCMB 2262 were grown to an $\mathrm{OD}_{600}$ of $0.2-0.4$, and were then diluted to a final $\mathrm{OD}_{600}$ of $0.01-0.04$ in flasks containing $15 \mathrm{ml}$ SWT broth. This procedure reduces carryover of any intrinsic autoinducer activity that the cells may have secreted into the growth medium. The cultures were grown with shaking at $16^{\circ} \mathrm{C}$ (the upper temperature limit at which these strains might be expected to coexist in nature), and the $\mathrm{OD}_{600}$ and luminescence (either with or without added decyl aldehyde) of culture aliquots were measured periodically. In some cases, the medium was supplemented with VAI-1 (Sigma-Aldrich) to a final concentration of 2.4-240 ng/ml. Cells of $V$. salmonicida were also exposed to VAI-1 at a final concentration of $2 \mu \mathrm{g} / \mathrm{ml}$ because lower concentrations of VAI-1 were not able to induce them to luminesce without the addition of aldehyde. These cells were grown to an $\mathrm{OD}_{600}$ of 0.8 and were then diluted to a final $\mathrm{OD}_{600}$ of $0.01-0.04$ in $15 \mathrm{ml}$ SWT broth, after which they remained luminous when exposed to aldehyde.

Effect of the addition of $V$. salmonicida spent-culture extract on the luminescence induction of $V$. fischeri ES114

$V$. salmonicida spent-culture extract was prepared as described by Nealson (1977). Briefly, strain NCMB 2262 was grown to a density of $2.9 \times 10^{8}$ cells $/ \mathrm{ml}$, and $1 \mathrm{l}$ cell-free spent medium was extracted with ethyl acetate and concentrated to a volume of $3.0 \mathrm{ml}$. The extract should contain any VAI-1-like acyl-HSL autoinducer produced by $V$. salmonicida. $V$. fischeri cells were grown to an $\mathrm{OD}_{600}$ of 0.4 and were then diluted to an $\mathrm{OD}_{600}$ of 0.05 in $15 \mathrm{ml}$ VHCM that contained an ethyl acetate extract from an equivalent of $15 \mathrm{ml}$ of a $V$. salmonicida culture at an $\mathrm{OD}_{600}$ of 4.8. Prior to adding the medium, the ethyl acetate solvent was allowed to evaporate completely, leaving any acyl-HSL produced by the $V$. salmonicida cells. $V$. fischeri cells were then grown with shaking at their temperature optimum $\left(28^{\circ} \mathrm{C}\right)$, and the $\mathrm{OD}_{600}$ and luminescence (both with and without added decyl aldehyde) of culture aliquots were measured periodically.

\section{Results and discussion}

$V$. salmonicida has not been previously described as being a luminescent species; however, because of recent evi- 
Fig. 1 Luminescence of Vibrio salmonicida strain NCMB 2262 grown in the presence $(\bullet, \bigcirc)$ or absence $(\square, \square)$ of Vibrio fischeri autoinducer $\mathrm{N}$-(3-oxo-hexanoyl)-L-homoserine lactone. Light emission of culture aliquots was measured at the indicated culture densities (OD values) either in the presence $(\mathbf{0}, \mathbf{\square})$ or in the absence $(\bigcirc, \square)$ of added decyl aldehyde. Essentially the same results were obtained when all five $V$. salmonicida strains were tested (1 luminescence unit [LU] = $1.7 \times 10^{3}$ quanta/s; the detection limit was $\left.10^{0} \mathrm{LU} / \mathrm{OD}\right)$

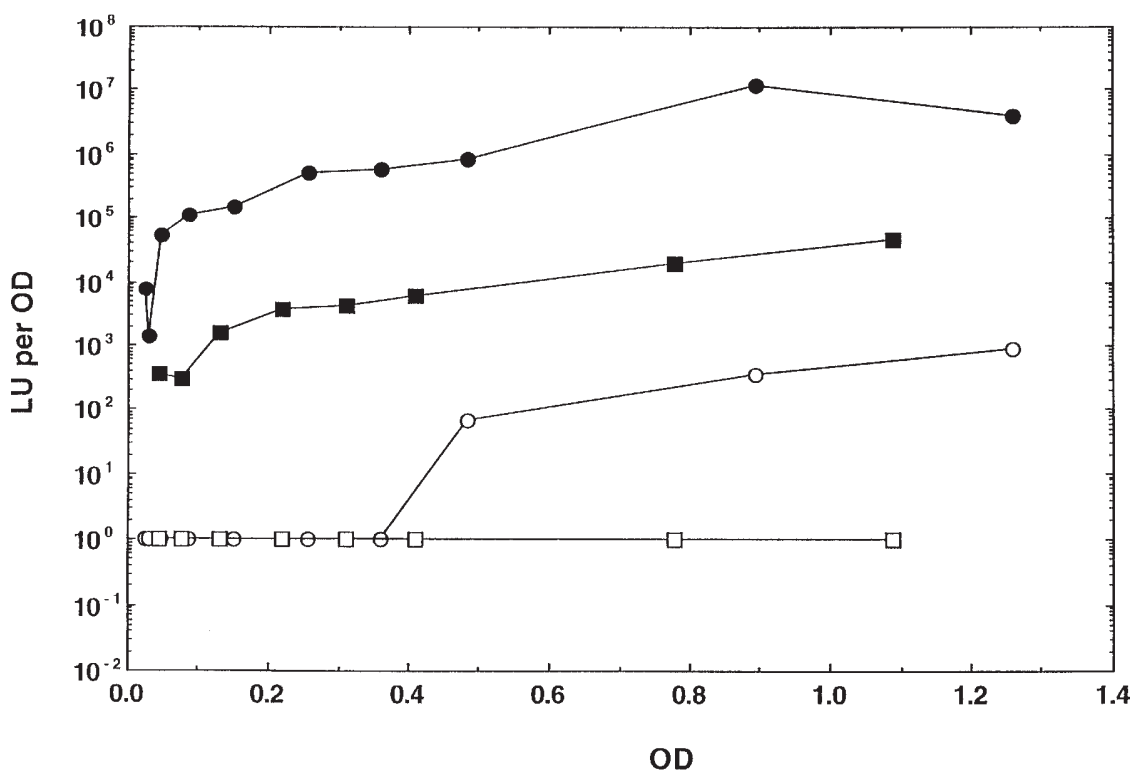

dence that the level of luminescence of $V$. logei is inhibited at elevated growth temperatures (Fidopiastis et al. 1998), colonies of $V$. salmonicida were assayed for luminescence during growth within its psychrophilic temperature range $\left(2-16^{\circ} \mathrm{C}\right)$. Colonies of $\mathrm{V}$. salmonicida were not detectably luminous over this entire range, either visibly or by sensitive photometry. However, if the colonies were exposed to decyl aldehyde, they immediately became visibly light-emitting, indicating that $V$. salmonicida is a luminous bacterium that expresses a luciferase but not all the cofactors normally required to produce light. Using an in vitro enzyme assay on cell lysates, we confirmed that the light was produced by a typical bacterial luciferase that required $\mathrm{FMNH}_{2}, \mathrm{O}_{2}$, and an aliphatic aldehyde. Further, analysis of luciferase enzyme decay kinetics (Table 1) revealed that the $V$. salmonicida activity grouped with the "fast-kinetics" enzymes of $V$. fischeri and $V$. logei, whose turnover rates are distinct from those of the slower luciferases of $V$. harveyi and related species (Nealson 1978).

All five $V$. salmonicida strains that we examined induced luminescence early in the exponential phase of growth regardless of either the medium (SWT or VHCM broth) or growth temperature $\left(8\right.$ or $\left.16^{\circ} \mathrm{C}\right)$ used, but in all cases exogenous aldehyde was necessary to detect luminescence. Because $V$. salmonicida cells grow faster in $\mathrm{SWT}\left(t_{\mathrm{gen}} \cong 3 \mathrm{~h}\right.$ at $\left.16^{\circ} \mathrm{C}\right)$ than in $\mathrm{VHCM}\left(t_{\mathrm{gen}} \cong 5 \mathrm{~h}\right.$ at $16^{\circ} \mathrm{C}$ ) medium, and luminescence induction was similar in all strains tested, cells of strain NCMB 2262 grown in SWT broth were used in subsequent experiments.

Induction of luciferase could be detected in cultures of V. salmonicida grown with or without added VAI-1 (Fig. 1) if aldehyde was added to an aliquot of the culture immediately before placing the aliquot in a photometer. The addition of VAI-1 to growing cells of $V$. salmonicida induced their luminescence approximately 100 -fold above the method's detection limit. Nevertheless, the luciferase of these cells apparently was still severely limited by their inability to supply adequate substrate aldehyde. Thus, the luminescence of VAI-1-induced $V$. salmonicida cells, measured in the presence of added decyl aldehyde, increased an additional 100-fold (Fig.1) to a level that is comparable to fully induced $V$. fischeri ES114 cells.

The ability of $V$. salmonicida to respond to $V$. fischeri autoinducer is consistent with these two species' phylogenetic proximity (Wiik et al. 1995; Fidopiastis et al. 1998). Similarly, the luminescence of the closely related species $V$. logei can also be induced in the presence of VAI-1 (data not shown), and V. logei has been shown to produce VAI-1 (E.P. Greenberg, University of Iowa, Iowa City, Iowa, USA; personal communication). Thus, these three closely related bacteria all respond to the same acyl-HSL autoinducer molecule. This finding is an example of how cells of several closely related species that can co-occur in nature might together act like a "quorum" of conspecific cells (Greenberg et al. 1979; Bassler et al. 1997; Visick and Ruby 1998).

Interestingly, the addition of VAI-1 apparently induced aldehyde synthesis in $V$. salmonicida, resulting in light emission (Fig. 1); however, this effect was not detected until approximately midway through exponential growth (i.e., at an $\mathrm{OD}_{600}$ of 0.4). The apparent temporal difference in expression of luciferase and aldehyde synthesis genes suggests that expression of these two sets of genes in $V$. salmonicida is subject to different regulatory controls.

Our work with $V$. salmonicida has led us to consider the following question: what is the cellular consequence of being a luminous bacterium that does not produce light? A "dark" pathway, in which luciferase (in the absence of aldehyde) catalyzes only a partial reduction of $\mathrm{O}_{2}$ by $\mathrm{FMNH}_{2}$, results in essentially no light production and leads to the formation of intracellular hydrogen peroxide (Nealson and Hastings 1977; Gonzalez-Flecha and Dem- 
Fig. 2 Luminescence of Vibrio fischeri ES114 cells grown in seawater-tryptone-yeast extract medium either with $(\mathbf{O})$ or without $(\bigcirc)$ the addition of an ethyl acetate extract of Vibrio salmonicida spent-culture medium (1 luminescence unit $[\mathrm{LU}]=1.7 \times 10^{3}$ quanta $/ \mathrm{s}$; the detection limit was $\left.10^{0} \mathrm{LU} / \mathrm{OD}\right)$

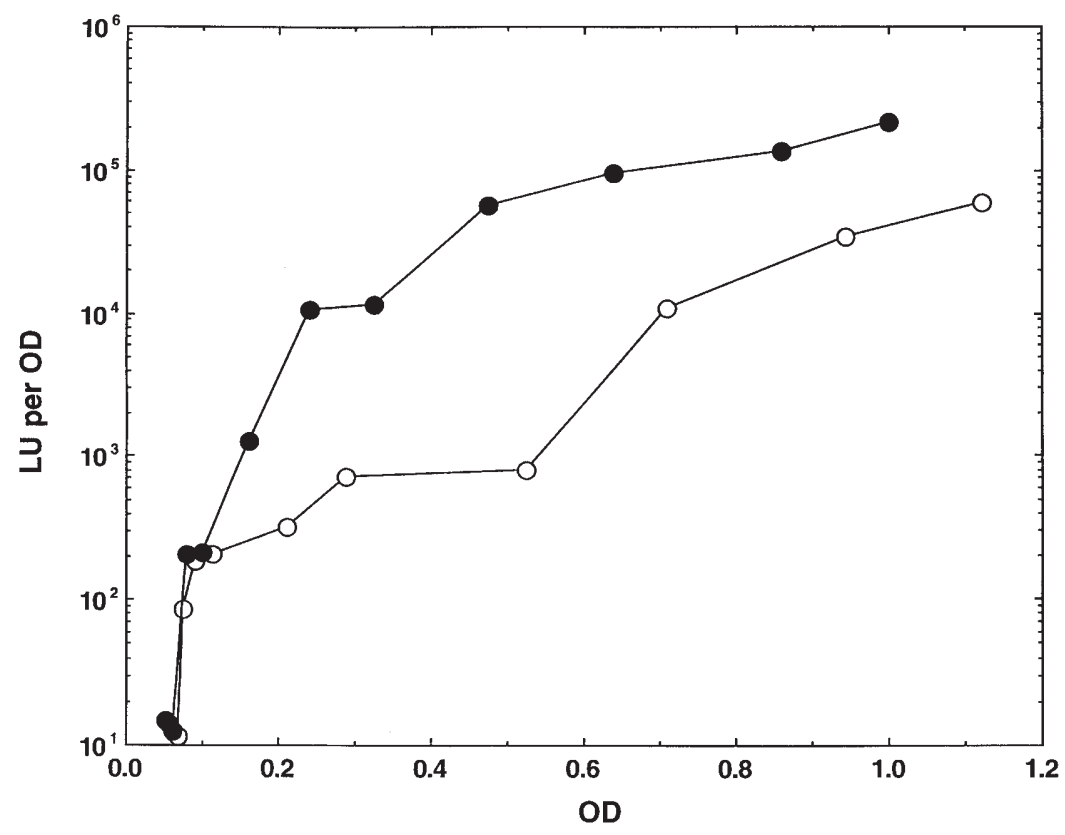

ple 1994). Our results with $V$. salmonicida suggest that this species may have significant dark-pathway activity in the absence of exogenous aldehyde, and thus might be subjecting itself to oxidative stress. Interestingly, $\mathrm{V}$. salmonicida appears to counteract this potentially growthlimiting oxidative stress by producing unusually abundant levels of catalase activity, which could be readily detected when a drop of hydrogen peroxide was added to isolated colonies on an agar surface (data not shown).

Ethyl acetate extracts of spent $V$. salmonicida medium enhanced specific luminescence in growing cultures of $V$. fischeri ES114, a natural underproducer of VAI-1 (Boettcher and Ruby 1990; Gray and Greenberg 1992), on the average approximately tenfold (Fig.2). This effect suggests that $V$. salmonicida produces a functional acylHSL autoinducer that can augment the luminescence induction effect of the endogenously produced autoinducer(s) (Kuo et al. 1994) of strain ES114. However, while addition of $V$. salmonicida culture extract to cells of $V$. salmonicida enhanced their level of luminescence up to threefold (data not shown), the enhancement by exogenous aldehyde remained, suggesting that $V$. salmonicida cells do not produce in culture an acyl-HSL that can fully induce sufficient aldehyde synthesis activity. Interestingly, among the three Vibrio species tested, the lowest $\mathrm{OD}_{600}$ at which luminescence was induced occurred at different levels of added VAI-1 (Table 2). This observation suggests that (1) the structure of VAI-1 may be different from that of the acyl-HSL(s) naturally produced by $V$. logei and $V$. salmonicida, and/or (2) these species may have acyl-HSL receptor proteins (LuxR homologues) with lower affinities for VAI-1 than does $V$. fischeri LuxR.

In summary, we have demonstrated that $V$. salmonicida (1) produces a typical bacterial luciferase with decay kinetics similar to those of light-organ symbionts of squids and fishes, (2) possesses the intrinsic ability to synthesize aldehyde, (3) can induce both luciferase and aldehyde synthesis genes in the presence of the acyl-HSL VAI-1, (4) produces an autoinducer activity that only slightly induces its own luciferase gene expression and does not detectably induce aldehyde synthesis, and (5) secretes an activity that can induce luminescence in cultures of $V$. fischeri. Both the precise organization and regulation of lux genes in $V$. salmonicida and their significance to the ecology of this bacterium remain to be revealed. $V$. salmonicida is typically found as a pathogen associated with decaying wound tissue of fishes (Sørum et al. 1988) and may produce hydrogen peroxide as a means of causing host tissue damage, as has been reported for pathogenic mycoplasmas (Razin 1986). We speculate that the suppression of light emission in $V$. salmonicida and the subsequent formation of hydrogen peroxide that may occur in the absence of an externally provided organic aldehyde could be a significant clue to its mechanisms of vir-

Table 2 Representative results of three experiments to determine the effect of Vibrio fischeri autoinducer $N$-(3-oxo-hexanoyl)-L-homoserine lactone (VAI-1) addition on the optical density $\left(\mathrm{OD}_{600}\right)$ at which luminescence is induced. Each strain was grown with shaking at $16^{\circ} \mathrm{C}$ in seawater-tryptone-yeast extract medium, and culture $\mathrm{OD}_{600}$ and luminescence were monitored. For Vibrio salmonicida only, decyl aldehyde $(50 \mathrm{ng} / \mathrm{ml})$ was added immediately before luminescence was measured. The lowest $\mathrm{OD}_{600}$ at which the specific activity of luminescence began to increase is reported as the point of induction

\begin{tabular}{lcccc}
\hline Strain & \multicolumn{5}{c}{ Optical density at induction } \\
\cline { 2 - 5 } & \multicolumn{4}{c}{ Concentration of added VAI-1 } \\
& 0 & 2.4 & 24 & 240 \\
\hline Vibrio fischeri ES114 & 0.6 & 0.04 & 0.04 & 0.04 \\
Vibrio logei SR6 & 0.8 & 0.15 & 0.06 & 0.04 \\
Vibrio salmonicida 2262 & 0.4 & 0.4 & 0.12 & 0.12 \\
\hline
\end{tabular}


ulence and perhaps even to the functional evolution of bacterial luciferase.

Acknowledgements We thank E. P. Greenberg for sharing unpublished data. This work was supported by National Institutes of Health grant no. RR12294 to E. G. Ruby and M. McFall-Ngai, and by National Science Foundation grant no. IBN96-01155 to M. McFall-Ngai and E. G. Ruby.

\section{References}

Bassler BL, Greenberg EP, Stevens AM (1997) Cross-species induction of luminescence in the quorum-sensing bacterium $\mathrm{Vib}$ rio harveyi. J Bacteriol 179: 4043-4045

Boettcher KJ, Ruby EG (1990) Depressed light emission by symbiotic Vibrio fischeri of the sepiolid squid Euprymna scolopes. J Bacteriol 172:3701-3706

Egidius E, Wiik R, Anderson K, Hoff A, Hjeltnes B (1986) Vibrio salmonicida sp. nov., a new fish pathogen. Int J Syst Bacteriol $36: 518-520$

Farmer JJ, Hickmann-Brenner FW (1991) The genera Vibrio and Photobacterium. In: Balows A, Truper HG, Dworkin M, Harder W, Schleifer KH (eds) The prokaryotes, 2nd edn. Springer, Berlin Heidelberg New York, pp 2952-3011

Fidopiastis PM, Boletzky SV, Ruby EG (1998) A new niche for Vibrio logei, the predominant light organ symbiont of squids in the genus Sepiola. J Bacteriol 180:59-64

Fuqua CW, Winans SC, Greenberg EP (1996) Census and consensus in bacterial ecosystems: the LuxR-LuxI family of quorumsensing transcriptional regulators. Annu Rev Microbiol 50: 727-751

Gonzalez-Flecha B, Demple B (1994) Intracellular generation of superoxide as a by-product of Vibrio harveyi luciferase expressed in Escherichia coli. J Bacteriol 176:2293-2299

Gray KM, Greenberg EP (1992) Physical and functional maps of the luminescence gene cluster in an autoinducer-deficient Vibrio fischeri strain isolated from a squid light organ. J Bacteriol $174: 4384-4390$

Greenberg EP, Hastings JW, Ulitzur S (1979) Induction of luciferase synthesis in Beneckea harveyi by other marine bacteria. Arch Microbiol 120:87-91
Hastings JW, Nealson KH (1977) Bacterial bioluminescence. Annu Rev Microbiol 31:549-595

Kuo A, Blough NV, Dunlap PV (1994) Multiple $N$-acyl-L-homoserine lactone autoinducers of luminescence in the marine symbiotic bacterium Vibrio fischeri. J Bacteriol 176:75587565

Makemson JC (1973) Control of in vivo luminescence in psychrophilic marine photobacterium. Arch Mikrobiol 93:347358

Nealson KH (1977) Autoinduction of bacterial luciferase. Arch Microbiol 112:73-79

Nealson KH (1978) Isolation, identification and manipulation of luminous bacteria. Methods Enzymol 57:153-166

Nealson KH, Hastings JW (1991) The luminous bacteria. In: Balows A, Truper HG, Dworkin M, Harder W, Schleifer KH (eds) The prokaryotes, 2nd edn. Springer, Berlin Heidelberg New York, pp 625-639

Razin S (1986) Mycoplasmal adherence. In: Razin S, Barile MF (eds) The mycoplasmas, vol 4. Academic Press, Orlando, pp 161-202

Reichelt JL, Baumann P (1973) Taxonomy of the marine, luminous bacteria. Arch Mikrobiol 94:283-330

Sørum H, Poppe TT, Olsvik Ø (1988) Plasmids in Vibrio salmonicida isolated from salmonids with hemorrhagic syndrome (Hitra disease). J Clin Microbiol 26:1679-1683

Sørum H, Hvaal AB, Heum M, Daae FL, Wiik R (1990) Plasmid profiling of Vibrio salmonicida for epidemiological studies of cold-water vibriosis in Atlantic salmon (Salmo salar) and cod (Gadus morhua). Appl Environ Microbiol 56:1033-1037

Visick KL, Ruby EG (1998) Considering the emergent properties of quorum sensing: the consequences to bacteria of autoinducer signaling in their natural environment. In: Winans SC, Dunny GM (eds) Cell-cell communication in bacteria. American Society for Microbiology Washington, DC, pp 333-352

Wiik R, Anderson K, Daae FL, Hoff KA (1989) Virulence studies based on plasmid profiles of fish pathogenic Vibrio salmonicida. Appl Environ Microbiol 55:819-825

Wiik R, Stackebrandt E, Valle O, Daae FL, Rødseth OM, Anderson K (1995) Classification of fish-pathogenic vibrios based on comparative 16S rRNA analysis. Int J Syst Bacteriol 45:421428 